\title{
Forum
}

\section{Clarence Thomas Defended}

Both as a political scientist and one who worked for Clarence Thomas for four years when he was Chairman of the EEOC, I find unprofessional and contemptible your anti-Thomas diatribe, presented as a symposium on "Politics, Values, and the Thomas Nomination"' (September 1992). Of the six essays, none defended Thomas's nomination, while three denounced him for his putative views and his presumed harassment of Anita Hill, and the other three criticized him or assumed the truth of Ms. Hill's charges against him. (I exempt from my specific criticisms the essay of Professors Mansbridge and Tate, who, while critical of Thomas, do engage in useful political analysis.)

Did symposium editor Marian Lief Palley, who is co-author of the contribution referring to the Judiciary Committee hearing as a "symbolic gang rape of an African-American woman," attempt to transcend her tendentiousness and secure presentations from political scientists outside the anti-Thomas mindset? To ask the question is to answer it. To recall examples: The essay by Professor Pinderhughes uncritically repeats NAACP propaganda about nominee Thomas's record. The public opinion essay by Frankovic and Gelb contributed nothing beyond what can be found in typical newspaper reporting. In a particularly vicious and often incoherent contribution, Professor O'Connor ridicules nominee Thomas for "his personal attempt to appear more scholarly than he feared he was." An honest review of the record readily refutes this and other wild assertions made by the symposium participants.

In a blindness typical of ideological fanaticism, none of the essays dealt directly with the simple but interesting question of the role of white racial prejudice in building (and sustaining) the case against nominee and now Justice Thomas.
(Mansbridge and Tate approach but avoid this issue.) This animus against a black conservative is the "lynching" that nominee Thomas astutely noted in his hearings, and that ideologically-charged screeds dismiss out of hand. Yet I realize that Justice Thomas's opponents simply do not know the man and his qualities of intellect and character that will make him an outstanding justice. For us political scientists the issue goes beyond him.

It is hard enough to support the activities of an APSA that promotes a political science that has little discernible relevance to the great questions and current issues of politics. It becomes unbearable when the organs of this professional association become indistinguishable from $M s$. magazine and interest-group propaganda.

Justice Thomas needs no apology to survive this silliness. But if they value scholarly integrity, the individuals responsible for this symposium must confess error in abandoning professional standards and apologize to the profession.

\section{Ken Masugi}

Former Special Assistant to EEOC Chairman Clarence Thomas, 1986-90

\section{The Wars of Watergate}

I was interested to read Professor Fred Smoller's piece concerning his course on Watergate. I was more than mildly surprised by his failure to cite Stanley Kutler's magisterial The Wars of Watergate as a possible text for use in such a class. The work was published in 1990 and thus should have been available to Professor Smoller. I realize that the hardback edition is expensive, and the length of the study perhaps works against its being used as a text for his undergraduates. But, since his $P S$ article is intended for others who might create such a course in the future, I am genuinely puzzled by his failure even to mention the book, which is surely the most comprehensive study of Watergate yet to appear; one, furthermore, with a clear and coherent thesis. As the work of a gifted historian well-versed in the intricacies of American law and politics, it has scholarly advantages over most other works on Watergate written by journalists or participants. It further has a great advantage over the Schell book which Professor Smoller chose as his text; that is the benefit of a 20 -year perspective and the availability of primary sources unavailable to Schell.

Robert J. Johnstone Earlham College

\section{Ethnic Conflict Conference Hosted by Defense Intelligence College}

On June 23 and 24, 1992, I was invited to participate in a conference on "Ethnic Conflict: Challenges to U.S. Security?" With the end of the Cold War in mind, this gathering was hosted by the Defense Academic Support Program of the Defense Intelligence College in Washington, D.C. More than 100 people were in attendance. For a scholar who normally operates in relative obscurity, this proved to be an exciting opportunity to present my research on the Kurdish conflict in Turkey, as well as interact with a number of other scholars and practitioners interested in similar subjects.

The conference was divided into two parts: (1) plenary papers, and (2) regional workshop point papers. The noted French scholar Gerard Chaliand presented the opening plenary paper: "A Geopolitical Map of Ethnic Conflict: Past, Present, and Future." Among other points, he noted that until the French Revolution, minorities were religious, not 
ethnic or linguistic groups. In the Muslim world this idea remained extant until very recently. Thus, the Kurds in Turkey were not considered to be a minority because they were Muslim, while the Armenians and Greeks, as Christians, were regarded as minorities.

Chaliand also argued that the Soviet Union, in part, collapsed because of its European minorities, not its Central Asian ones. Given the large Russian minority in Kazhakstan, he felt that this new state would eventually be partitioned between Russia and the Kazhaks.

I was particularly interested in hearing and meeting with Chaliand because I had cut my research teeth on Armenian and Kurdish matters by reading his earlier works. I was not disappointed. Later that evening he and I even surveyed two of Washington's interesting used book stores, a pastime for which we discovered we each had a mutual affinity.

Donald Horowitz, whose seminal study Ethnic Groups in Conflict, 1985, served as the backdrop for the entire conference, presented the next plenary paper. In his remarks he drew and elaborated upon some of the ideas proffered in his book which had pointed out that Bangladesh had been the only successful example of secession since World War II. The recent example of the Eritrean secessionist movement, however, augurs further success for such groups. The long stability of the borders in Africa may be over. The disintegration of the Soviet Union by consent and Yugoslavia by force reinforces this trend.

Indeed, argued Horowitz, the ethnic question promises to be the most important question of the 21st century. To avoid following the rest of the world down this "hellish path of ethnic violence," the U.S. must remember its history and principles of a working, moderate democracy that recognized that majorities are not always correct.

Following lunch, the conference broke down into six different regional workshops for which short point papers served to stimulate audience discussion. Charles MacDonald of Florida International University and I presented papers on the Kurds for the Middle East workshop, while other workshops were held at the same time on Latin America, Africa, Southeast Asia, South Asia, and Europe.

There were some thirty people at my workshop-which also included a point paper on the situation in the Caucasus by Mark Saroyan of Harvard. The audience interaction which followed our brief presentations proved wide-ranging.

The only problem in these simultaneous meetings of six different workshops was that I missed the other five. This difficulty was only partially alleviated by each conference participant being presented a hefty set of all the papers which were to be presented. Nevertheless, I thought the workshop procedure was a useful way to permit specialization that otherwise would not have been possible.

The second and final day of the conference saw the presentation of plenary papers by (1) Myron Weiner of MIT: "Immigration and Ethnic Conflict in South Asia"; (2) Nelson Kasfir of Dartmouth College: "State and International Responses to Ethnic Violence in Africa"; (3) F. Stephen Larrabee of Rand Corporation: "Ethnic Conflict in the Balkans: Implications for Europe" (presented by Ivan Volgyes of the University of Nebraska-Lincoln); and (4) a presentation by Ted Robert Gurr of his continuing empirical research which is scheduled to be published next year as Minorities at Risk: Origins and Outcomes of Ethnopolitical Conflicts.

Both in his presentation and in my personal conversations with him, Professor Weiner illustrated how it is eminently possible for a distinguished scholar to present sophisticated concepts in a down-to-earth, easy-tounderstand style, as well as being pleasant to and considerate of others. During dinner, Weiner also owned that after a long day on the job, he liked to unwind by cooking the evening meal which apparently had become somewhat of another art for him.

As a result of this conference on ethnic conflict, I believe that all the participants came away with a better understanding of what is certain to continue to be one of the great problems of the future. The Defense
Intelligence College and its Director of Academic Research, Robert Slater, are to be commended for their continuing efforts "to provide for direct contact and scholarly exchange between defense analysts, college faculty, and noted experts on Third World issues."

Michael M. Gunter

Tennessee Technological University

\section{Network Resources for Political Scientists}

Author's Note: This is a longer version of an article that first appeared in the APSA's Computer Users Group Newsletter, Winter 1992, pp. 7-12.

As information technology becomes more commonplace in higher education, faculty members in various fields find themselves relying on some of the network resources for valuable information in their areas of specialization. There is a wealth of information to be found in the networks for different fields of study. In this paper I would like to address the various sources of information which the political scientist can rely on and make use of in the various areas of political science. Thus, we will take a look at what network sources are available, where they can be found, what to do to get to them, how to use them, what sources to make use of in order to obtain maximum information. Then we can also address the question of how they can be incorporated in various courses and how useful they can be to the individual faculty member who chooses to invest some time in learning about these resources.

There are several networks that academic institutions may be linked to. Two of the more common ones are BITNET and INTERNET. BITNET is a network of mini or mainframe computers connecting many universities and colleges allowing for a mail store and forward capability. The INTERNET is also a collection of networks which makes use of the TCP/IP protocols for exchanging information. Depending on which one an institution is linked to, one can have access to various BITNET and INTERNET listservers. 


\begin{tabular}{|c|c|c|}
\hline Network-wide ID & Full Address & List Title \\
\hline AFAM-L & AFAM-L@UMCVMB & African-American Research \\
\hline AFRICA-L & AFRICA-L@BRUFPB & FORUM PAN-AFRICA \\
\hline AFROAM-L & AFROAM-L@TEMPLEVM & $\begin{array}{l}\text { African American Issues in Higher } \\
\text { Education }\end{array}$ \\
\hline AJBS-L & AJBS-L@NCSUVM & $\begin{array}{l}\text { Association of Japanese Business Studies } \\
\text { List }\end{array}$ \\
\hline AMNESTY & AMNESTY@JHUVM & Amnesty International List \\
\hline APNET-L & APNET-L@JPNSUT00 & Asia Pacific Network \\
\hline ASA-L & ASA-L@TAMVM1 & $\begin{array}{l}\text { African Students Association Discussion } \\
\text { List }\end{array}$ \\
\hline \multirow[t]{2}{*}{ BALT-L } & BALT-L@UBVM & (Peered) Baltic Republics Discussion List \\
\hline & BALT-L@UKACRL & (Peered) Baltic Republics Discussion List \\
\hline BUDDHA-L & BUDDHA-L@ULKYVM & Buddhism Discussion Group \\
\hline BUDDHIST & BUDDHIST@JPNTOHOK & Forum on Indian and Buddhist Studies \\
\hline CANADA-L & CANADA-L@MCGILL1 & Canadian Issues Forum \\
\hline CANALC & CANALC@YORKVM1 & $\begin{array}{l}\text { Canadian Association for Latin American } \\
\text { and Caribbean }\end{array}$ \\
\hline CANALC-D & CANALC-D@YORKVM1 & $\begin{array}{l}\text { Latin American and Caribbean Digest } \\
\text { from CANA }\end{array}$ \\
\hline CELTIC-L & CELTIC-L@IRLEARN & CELTIC-L-The Celtic Culture List \\
\hline CENTAM-L & CENTAM-L@UBVM & Central America Discussion List \\
\hline CHILE-L & CHILE-L@PURCCVM & Discussion Regarding Chile \\
\hline \multirow[t]{2}{*}{ CHILENET } & $\begin{array}{l}\text { CHILE-L@UCHCECVM } \\
\text { CHILENET@UCHCECVM }\end{array}$ & $\begin{array}{l}\text { Informaciones y Cultura acerca de CHILE } \\
\text { (Peered) Lista de Informaciones para la } \\
\text { Red A }\end{array}$ \\
\hline & CHILENET@UTFSM & $\begin{array}{l}\text { (Peered) Lista de Informaciones para la } \\
\text { Red A }\end{array}$ \\
\hline CHINA & CHINA@PUCC & Chinese Studies List \\
\hline CHINA-ND & CHINA-ND@KENTVM & China News Digest (US News) \\
\hline CHINA-NN & CHINA-NN@ASUACAD & China News Digest (Global News) \\
\hline CHINA-NT & CHINA-NT@UGA & $\begin{array}{l}\text { China-Net (The Coordination Network for } \\
\text { IFCSS) }\end{array}$ \\
\hline CHINANET & CHINANET@TAMVM1 & CHINANET: Networking in China \\
\hline CNC-L & CNC-L@UVVM & China News (Canada) \\
\hline CND-EP & CND-EP@IUBVM & China News Digest-Europe/Pacific \\
\hline CND-OSU & CND-OSU@OHSTVMA & $\begin{array}{l}\text { CND-OSU China News Service for Eastern } \\
\text { USA }\end{array}$ \\
\hline EC & EC@INDYCMS & European Community \\
\hline ECONOMY & ECONOMY@TECMTYVM & $\begin{array}{l}\text { Economic Problems in Less Developed } \\
\text { Countries }\end{array}$ \\
\hline GLOSAS-L & GLOSAS-L@UOTTAWA & $\begin{array}{l}\text { GLObal Systems Analysis and Simulation } \\
\text { List }\end{array}$ \\
\hline GOVDOC-L & GOVDOC-L@UALTAVM & $\begin{array}{l}\text { (Peered) Discussion of Government } \\
\text { Document Issues }\end{array}$ \\
\hline GRANT-L & GRANT-L@UA1VM & OSP Funding Alert List \\
\hline GRANTS-L & GRANTS-L@JHUVM & $\begin{array}{l}\text { NSF Grants \& Contracts Bulletin Board } \\
\text { Bitnet }\end{array}$ \\
\hline HUNGARY & HUNGARY@UCSBVM & Hungarian Discussion List \\
\hline INDIANWS & INDIANWS@PCCVM & The India List (NeWS) \\
\hline J-FOOD-L & J-FOOD-L@JPNKNU10 & Japanese Food \& Culture Discussion List \\
\hline JAPAN & JAPAN@FINHUTC & Info-Japan \\
\hline JEM & JEM@MITVMA & Jewish Electronic Mail Conference \\
\hline JEP-BB & JEP-BB@CSEARN & $\begin{array}{l}\text { Networking for Universities in Central } \\
\text { Slovak }\end{array}$ \\
\hline MCLR-L & MCLR-L@MSU & $\begin{array}{l}\text { MIDWEST CONSORTIUM FOR } \\
\text { LATINO RESEARCH }\end{array}$ \\
\hline PAKISTAN & PAKISTAN@ASUACAD & Pakistan News Service \\
\hline PEACE & PEACE@INDYCMS & Peace Studies \\
\hline POLCOMM & POLCOMM@RPIECS & Study of Political Communication \\
\hline POLI-SCI & POLI-SCI@RUTVM1 & Political Science Digest \\
\hline $\begin{array}{l}\text { RUSSIA } \\
\text { RUSSIAN }\end{array}$ & $\begin{array}{l}\text { RUSSIA@INDYCMS } \\
\text { RUSSIAN@ASUACAD }\end{array}$ & Russia \& Her Neighbors \\
\hline SEANET-L & SEANET-L@NUSVM & Southeast Asian Studies List \\
\hline SM-LADB & SM-LADB@UNMVM & Latin American Data Base \\
\hline STATEPOL & STATEPOL@UMAB & Politics in the American States \\
\hline TAMIL-L & TAMIL-L@DHDURZ1 & TAMIL-L Tamil Studies \\
\hline TUNISNET & TUNISNET@PSUVM & The Tunisia Network \\
\hline $\begin{array}{l}\text { UN } \\
\text { WMST-L }\end{array}$ & $\begin{array}{l}\text { UN@INDYCMS } \\
\text { WMST-L@UMDD }\end{array}$ & United Nations \\
\hline & & \\
\hline
\end{tabular}

\section{LISTSERVERS}

LISTSERVERS are host computer centers which distribute electronic mail and files either by subscription or by single request. There are hundreds of listservers set up for all types of topics. A listserver can be a storehouse of information for various topics. What I have done is to cull from one of these listservers the topics that I thought would be of interest to political scientists. The LISTSERV political science related lists known to one listserver, LISTSERV@BITNIC, as of January 15, 1992, are printed here.

As one can see from this short collection there are discussion lists for all kinds of topics. Some cover a wide area and general topics such as Politics in the American States and the United Nations list. Some cover specific countries in Asia, Africa, Latin America and Eastern Europe such as those that cover India, China, Tunisia, Pakistan. Others provide news services that keep one up to date with what is going on in each of these countries sometimes on a daily basis so that one can monitor news as it happens, as in the example of the history professor from the University of Wisconsin-Eau Claire who monitored the Soviet coup through a Baltic states list (Oberly). I often use the China News Digest to help me monitor what is going on in China and feed such news to my students in an Asian Government and Politics course in order to get them interested in global issues and events (Manrique 1991, 218).

Some lists like the Women's Studies list have been a useful resource for syllabi exchange and for information about texts to use in Women's Studies courses. Conference listings, calls for papers, collaborative writing efforts, and job openings are posted in the list. When major issues are brought to the fore, such as when the Clarence ThomasAnita Hill hearings were held and when the Rodney King trial and ensuing California riots took place, a discussion of the various points and issues took place among the subscribers to the lists like XCULT-L and WMST-L.

In order to obtain access to any of these lists one needs to have access to the institution's main computers and 
have an account with that computer. Then the individual will need to subscribe to the lists of interest to him/ her. To subscribe to any of these lists one needs to send an electronic mail message to LISTSERV@BITNIC.BITNET and in the body of the message type in only the command SUB UN (you can substitute the name of any list that you wish to join in this spot. I have chosen to use the UN list as an example) Cecilia Manrique (and you substitute your first and last name here so that the listserver recognizes you as the subscriber). Thus, the full body of the text should read:

\section{SUB UN Cecilia Manrique [use your name]}

Some lists are more active than others so be prepared to either not receive too much mail traffic or be overwhelmed by a lot of messages which can average in the hundreds a day. If you find that a list gets to be overwhelming for you and some of the discussions are not to your advantage you can unsubscribe to the list by sending a message to the same listserver with the message: UNSUB UN Cecilia Manrique [use your name] and this should take you out of the list. Reading your mail conscientiously and screening them like you would ordinary junk mail would allow you to keep your account in order.

\section{Accessing Remote Library Catalogs and Databases}

TELNET is a type of program which gives the user the ability to establish a connection with a remote computer connected to the INTERNET. One can access other computers using TELNET from the $\$$ prompt of a VAX computer account. TELNET makes remote login possible by typing in the Telnet command together with the remote computer's address from the $\$$ prompt. Once the user gets into the remote computer each site will have a set of commands and procedures to follow. Trying them and experimenting with them is the only way to learn. Here are a few addresses of services and libraries to try:

\section{You can get into a service from}

the Cleveland Freenet which shows you the headline news in USA TODAY. In order to do that follow these instructions:

a. Type in TELNET 129.22.8.76.

b. $\log$ in as a visitor which is choice 2 in the first screen.

c. Choose to explore the system which is option \#2 in the next screen.

d. Just press the RETURN key until you get a series of menu choices in front of you. From that menu you can choose \#15 or you can choose to type in GO USA. This will take you to the USA TODAY menu.

e. Within the news service, look at the bottom of the screen for the various commands to use. Pressing the SPACEBAR usually allows you to page through the news. Pressing the letter $Q$ allows you to quit and using the letter $\mathrm{H}$ will provide help.

f. When done reading the news, in order to exit the service type $Q$ to quit.

2. A library you can explore is the Marquette University Library which holds quite a collection. In order to gain access use the following command from the $\$$ prompt:

\section{TELNET 134.48.20.1}

At the login prompt type in the letter $\mathrm{M}$. When asked for the terminal type just type in $\mathrm{V}$ and press the ENTER key to confirm. You can undertake a word search by typing in $\mathrm{W}$ and a word such as Nigeria. The search will bring up the various documents in their collection which has the term NIGERIA in the title. You can browse through the list or take a look at each of the descriptions for the documents. When done you can initiate a new search by typing in the letter $N$. This will bring you to the main menu from which you can choose to do another search or choose to quit by typing in the letter $Q$.

3. A few other library addresses to try are the following:

University of Wisconsin-Madison: 128.104.198.20

University of Michigan: 35.1.48.149
Boston University: 128.197.130.200

University of Delaware: 128.175.13.6

Dartmouth University: 129.170.16.11

\section{Uses in the Political Science Classroom}

The ability to make use of what is on the network is limited only by one's imagination and one's willingness to explore. I have found this an effective way to draw my students out of learning merely from books which are often outdated into learning from what transpires around them. It allows them to be more confident of critically taking a look at the reliability of sources that are fed to them through various media. As an exercise I let my students experience the various aspects of what is available on the network. This is done during one computer session I hold a few weeks into the semester. I help them in whatever way I can to make use of these resources not only in my course but in other courses as well. In fact I encourage them to constantly provide me with feedback about how they and $I$ are doing during the course of the semester. For the most part students are awed by the new experience. Some take to it willingly especially when they have a positive experience with the computers and others fall by the wayside if they cannot get the system to function for them.

\section{Where To Go For Help}

The political scientist's first recourse is usually to find the "experts" in the field who can point them to the use of their own system. Most institutions have computing centers and some may even have a department dedicated to academic computing, an arm of the center that services the needs of faculty who wish to incorporate computing in their courses. These members of the staff should be able to help one unravel the mysteries of the individual system they have in their institution in order to obtain the links to these various networks. Members of the staff should be able to point out to the faculty member what is possi- 
ble or not possible within their given areas of specialization.

Once one gets into the network, one will find that there are a lot of friendly people out there who are more than willing to help a colleague in need of guidance. One of my first and most embarrassing experiences in the list was sending a subscription notice not to the listserver but to every member of the discussion group, which was not my intention. A couple of messages were sent to me informing me of my folly. I learned my lesson and was not discouraged by it. I still belong to many lists. And I am still willing to learn.

There are a lot of resources out there that are waiting to be tapped. One just has to venture into the unknown.

If I can be of any help to you as you venture into this experience send me a mail message at:

MANRIQUE@UWLAX.EDU or MANRIQUE@UWLAX.BITNET

\section{References}

Chew, John. 1990. "Inter-Network Mail Guide."

Kroll, Ed. 1989. "The Hitchhiker's Guide to the Internet." University of Illinois, Urbana-Champaign. September.

LaQuey, Tracy L. 1989. "Networks for Academics." Academic Computing, Vol. 4, No. 3, pp. 32-39, November.

Manrique, Cecilia. 1991. "Bringing the World Into the Classroom Via Electronic Mail." Proceedings: SIGUCCS User Services Conference XIX, pp. 211-18.

Martin, Jerry. 1991. "There's Gold in Them Thar Networks! Or Searching for Treasure in All the Wrong Places." Proceedings: SIGUCCS User Services Conference $X I X$, pp. 219-27.

Oberly, Jim. 1991. "The Contemporary Historian as Observer: Current Events on the Network." Computing and Networking Services Newsmemo. University of Wisconsin-Eau Claire, December, p. 11.

St. George, Art, and Ron Larsen. 1990.

"Internet Accessible Library Catalogs and Databases." November.

Cecilia G. Manrique

University of Wisconsin-La Crosse

\section{Emile}

Jean Jacques Rousseau

Took great pains to show

He was the perfect tutor for the fictional Emile

But he left by the door of the foundling home the babies he fathered for real.

\section{Niccolo Machiavelli}

Unemployed, Old Nick

Sought a Medici-an job

For teaching them the trick

Of how to rule the mob.

Informed already, they paid him no attention,

Begetting, thus, two popes, two queens, and dukes too numerous to mention.

\section{Thoreau}

Thoreau went into Walden wild (Though still in Concord's sphere) There to live like Nature's child (But only for a year). 